\title{
Benefits of 0.025" guidewires for ERCP
}

\author{
David L. Diehl
}

Received: 4 December 2013 / Accepted: 9 January 2014/Published online: 12 February 2014

(C) Springer Science+Business Media New York 2014

We read with interest the recent randomized study of 0.035 " versus 0.025 " guidewires for endoscopic retrograde cholangiopancreatography (ERCP) [1]. The authors correctly point out that, to show superiority (or even noninferiority), of one wire over another, "thousands" of patients would likely need to be enrolled in a prospective randomized study. We ran a power analysis assuming a $10 \%$ difference in cannulation success with one or the other guidewire, and came up with a number needed of 906.

But the smaller gauge guidewire confers advantages beyond a theoretical increase in cannulation success or decreased complication rate. For one thing, the smaller gauge wire occupies less space in the lumen of the catheter or endoscope, and as a result it is easier to pass devices over the wire and to conduct over-the-wire exchanges. In cases that require more than one guidewire, the 0.025 " guidewire occupies less space in the therapeutic channel of the endoscope, allowing easier passage of subsequent devices and stents.

The use of the Olympus VisiGlide 0.025" guidewire (Olympus Medical, Center Valley, PA, USA) was a good choice for this study, since the stiffness is comparable to a regular 0.035 " guidewire. Other 0.025 " guidewires have less 'body', and passage of devices and stents over them may be more difficult.

Guidewire technology continues to advance, and the current high-performance guidewires can lead to increased procedural success in difficult ERCP cases, particularly for complex pancreatic or biliary strictures. Simply looking at cannulation rates and incidence of complications does not give the full picture of the possible benefits of smallergauge wires. The day may come when the 0.035 " guidewire may be a device of historic significance only, fading into extinction in a similar way to ERCP devices like the 12-Fr plastic biliary stent, the single-lumen ERCP cannula, or the long-nose sphincterotome.

\section{References}

1. Halttunen J, Kylänpää L (2013) A prospective randomized study of thin versus regular-sized guide wire in wire-guided cannulation. Surg Endosc 27:1662-1667
D. L. Diehl ( $\square)$

Gastroenterology and Nutrition, Geisinger Medical Center, Danville, PA, USA

e-mail: dldiehl@geisinger.edu 